\title{
Platform urbanism and the Chinese smart city: the co-production and territorialisation of Hangzhou City Brain
}

\author{
Federico Caprotti - Dong Liu
}

Accepted: 11 October 2020/Published online: 3 November 2020

(C) Springer Nature B.V. 2020

\begin{abstract}
We analyse an urban platform (Alibaba's City Brain) to show how smart city development is evolving in urban China. In order to do so, we base our analysis on two strands of literature: that on platform urbanism, and on the experimental city. The paper identifies two processes that are shared across both bodies of work on platform urbanism and experimental cities: relational co-production and territorialisation. These processes can also be applied to the case of City Brain as both a platform and an urban experiment. We conclude by reflecting on the significance of urban platforms on the co-production of data-enabled urban governance; local urban context; and citizenship.
\end{abstract}

Keywords Smart city - Platform urbanism - Chinese cities - Urban digital governance $\cdot$ Artificial intelligence

\section{Introduction}

Over the past 30 years, China has experienced hyperrapid urbanization and unprecedented economic growth (Wu 2002). This has been accompanied by

F. Caprotti $(\bowtie) \cdot$ D. Liu

Department of Geography, School of Life and Environmental Sciences, University of Exeter,

Exeter EX4 4SB, UK

e-mail: f.caprotti@exeter.ac.uk the rapid development of Information and Communications Technology (ICT), including digital technologies such as cloud computing and the Internet of Things (IoT). At the same time, China has implemented industrial and governance strategies aimed at moving away from technological and industrial dependence on wealthier countries in order to pursue a national developmental path and challenge the existing global economic order (Hong 2017; Wu and Gereffi 2018). This affected many foreign technology firms, including Google, Facebook and Twitter, leaving domestic niche space for home-grown corporations such as Baidu, Alibaba and Tencent ( $\mathrm{Wu}$ and Gereffi 2018), commonly and collectively referred to as the BATs (Jia et al. 2018). Because of the rise to prominence of Huawei, another domestic technology firm, in this paper we refer to BATH rather than BAT.

During this trajectory of rapid growth, the Chinese state has attempted to strategically promote specific models of urban development. These have included eco-cities (Wu 2012; Lin 2018) and low-carbon cities (de Jong et al. 2013), both aimed at the imperative of greening urban development while stimulating the development of a national green economy (Pow 2018). Over the past 10-15 years, attention has increasingly shifted to digitally-enhanced urbanism (Zhen et al. 2015): the state has promoted smart city development as a central part of government agendas since at least the early 2010 s. 
In this context, smart city projects developed and trialled by domestic technology corporations are emerging and expanding. Wu et al. (2018) report that all sub-provincial cities, $89 \%$ of prefecture-level cities (a total of 241 cities), and $47 \%$ of county-level cities (51 cities) are developing smart city activities. BATH firms have become the biggest players in China's smart cities development, a marked contrast to the 2000s, when Western firms such as IBM dominated the domestic Chinese digital city market. Indeed, as will be shown below, not only are the BATHs and other domestic corporations predominant on the Chinese urban futures stage: their products and models are now sold domestically and exported internationally, as seen by the export to Malaysia of Alibaba's City Brain smart city management platform.

We use the case study of City Brain to make an empirical and theoretical contribution. Empirically, we show how Chinese technology corporations have developed and marketed smart city products that are both city-specific, but that can also be modified and applied to other Chinese cities. In turn, this enables us to identify and analyse the twin processes of: (a) coproduction of smart cities by a range of stakeholders from the spheres of government and the private sector, and (b) the territorialisation of smart urban platforms in China. We understand territorialisation here as the process whereby smart urban platforms are influenced by place and scale, and vice versa (Battaglini et al. 2016). Theoretically, the paper is contextualised by establishing a dialogue between literatures on platform urbanism, and on experimental cities (Caprotti and Liu 2020). In this light, the City Brain case is treated as an example of both an urban platform, and as an urban experiment that was intended, from the outset, to be replicable and scalable.

Platform urbanism is not only an emergent concept, but a complex one: it is key to remain conscious of key complexities related to this developing notion. In analysing the co-production of the platform city by firms, the state, and municipal authorities, we are responding to calls, in the recent literature, for a research focus that moves beyond binary analyses of either corporate visions and market-making around the smart city, or state-led initiatives. By understanding the roll-out of projects such as City Brain as the result of a complex and multi-scalar system of coproduction, we seek 'to avoid the pitfalls of approaching "smart" as a binary descriptor' (Gaffney and
Robertson 2018, p 49). The emergence of the Chinese platform and smart city, we argue, is the result of shifting interactions between state actors (at various scales), the private sector, and actor categories that don't neatly fit into either state or private sector, such as State-Owned Enterprises (SOEs).

We argue that two characteristics of both platform and experimental urbanism can be applied to the case of City Brain. The first of these is the relational coproduction of both platforms and urban experiments. The second is the importance of geographies of scale (Paasi 2004; Swyngedouw and Heynen 2003) in (a) materialising urban platforms (because they need to be fixed in the city); and (b) materialising urban experiments (because they are predicated on a view of the city as either a laboratory or a field site) (Evans 2011; Karvonen and van Heur 2014; Cossetta and Palumbo 2014).

The findings of this paper are based on research conducted on, and in, Hangzhou as a smart city case study. Semi-structured elite interviews with policymakers and technology corporation executives (both Alibaba and local technology firms) were carried out over the course of two field visits in 2018, totalling two months (Empson 2018). A total of 11 interviews with technology corporation executives, and five interviews with city officials, were carried out. Two taxi drivers were also interviewed, so as to gain a grounded perspective on the lived experience of City Brain.

Another methodological inroad into understanding the development of City Brain was attendance and observation at tours, site visits and industry conferences. Attendance at these events was organised so as to gain exposure to digital research and private sector environments relevant to smart urban platforms. While we did not carry out interviews at these events, it is widely recognised that ethnographic work and participant observation at these venues can yield insights into networks of co-production and relationality (Nyqvist 2017; Nyqvist et al. 2017; Sampson and Turgo 2018). These included tours with Alibaba and Tencent in Hangzhou, and a separate, specifically City Brain-focused tour. Tours were guided and were occasions for observational research. Our research also included two site visits to digital economyfocused city government sites. Attendance at an Alibaba marketing event focused on the development of cloud marketing systems was also part of our observational work. 
Hangzhou was chosen as a field site because Alibaba's City Brain platform was developed by the firm in conjunction with the city government, prior to its roll-out in the city in 2016, and the integration of Artificial Intelligence (AI) as part of the system from 2017 onwards. In addition, focusing on City Brain was useful due to the rapid and widespread adoption of the platform by cities in China (including Special Administrative Regions such as Macau), as well as its international impact. Finally, in order to ensure that our research was informed by the current developments in corporate-enabled platform urbanism, trade fairs and industrial shows were attended in Hangzhou, Chongqing and Shanghai. This enabled immersion in time-limited, concentrated relational environments (Schuldt and Bathelt 2011) where the technologies, systems and policies relevant to this paper were being discussed.

The way in which platforms such as City Brain influence the co-production and governance of the city by networks of (largely corporate and policy, but rarely grassroots) actors; the changing role of the urban citizen; and the importance of critically teasing apart corporate-state relations in the production of the many actually-existing smart city visions and projects worldwide (Mouton 2020; Shelton et al. 2015; Shelton and Lodato 2019) will be key to understanding and engaging with the production of the urban future. In the next section, we outline the development of Alibaba's City Brain platform in Hangzhou, before moving on to outline our conceptual framework. This is followed by analysis of its co-production and territorialisation. The paper concludes with a brief discussion.

\section{City brain: context and scope}

Alibaba's City Brain is one of a suite of data-focused 'brain' products. These include Industry Brain (including equipment maintenance forecasting, key factor identification, and the like), Aviation Brain (including gate planning, ground control, flight scheduling), Medical Brain (image recognition, medical data integration), and Environment Brain (waste management and environmental data support). City Brain was launched in 2016, with Hangzhou as a trial city and the official start date in October that year, after an initial request from the city administration (in April
2016), for help with finding solutions to Hangzhou's traffic problems (Alibaba Cloud 2018). Hangzhou is the capital of Zhejiang Province, and is situated at the head of Hangzhou Bay, roughly equidistant between the cities of Shanghai and Ningbo.

City Brain is based on a digital platform that, in its first iteration (City Brain 1.0), utilised data from sensors on traffic lights and embedded in traffic cameras. Cloud computing is used to process real-time data gathered from the sensor network, to optimise traffic flow by managing the timing of traffic lights. In addition, control over traffic light scheduling has enabled the optimisation of transport flows for emergency response vehicles (Min et al. 2018), such as the creation of 'green light corridors' through the city when fast response times are needed.

In 2018, City Brain was updated to version 2.0. The expansion was technological as well as territorial. The system was expanded to cover three city districts with a total areal coverage of $420 \mathrm{~km}^{2}$ (equivalent to just over roughly half the areal extent of New York's five boroughs). The sensor network was expanded to cover 1300 traffic lights, representing c. $25 \%$ of the three districts' crossroads (additionally, data from 3500 traffic cameras was linked into the platform). The system processes data in real-time based on current traffic status, an index of delays and traffic jams, and traffic speed information (Zhejiang online 2018). A force of 200 traffic police officers are directly linked to the system so as to enable response to be as rapid as possible (Sina 2018). Officers are dispatched to incidents not via operatives in a dispatch centre, but automatically by City Brain via smartphone alerts (Hsu 2018).

In June 2020, the system was further upgraded and updated to version 3.0, focusing on closer integration of digital data (Hangzhou City website 2020). The updated system is described as enhancing the city's digital 'immunity' to events such as natural disasters and pandemics such as the 2020 Covid-19 disease, by enabling modelling of unfolding events, and suggesting intelligent responses. Sources reporting on City Brain 3.0 use the example of a typhoon: City Brain 3.0 will, it is reported, be able to track a typhoon before it makes landfall, model its potential path through a city, and activate emergency response systems and resources through advance warning (LinkingAPI website 2020). The development of City Brain 3.0, in turn, is seen as a key next step in the future 
influencing of global urban development by Chinese digital innovation: 'A hundred years ago, London exported the subway to the world, Paris exported the sewer, and New York exported the power grid. Today, the value of digital leadership in Chinese cities has been highlighted, and the establishment of a new digital foundation has become the foundation for the evolution of future cities' (Ibid.).

The platform was declared a success as early as 2017 by Alibaba (Alibaba Cloud 2018). Positive outcomes reported included an increase in average travel speeds by $15.3 \%$, and a peak hour congestion rate reduction of $9.2 \%$. Overall, Alibaba claims that this has resulted in a reduction in transit times of around three minutes per passenger-journey (Alibaba Cloud 2018). A 2020 report to the US-China Economic and Security Review Commission reported that as a result of City Brain, Hangzhou had fallen from fifth most congested city in China, to 57th (Atha et al. 2020). In terms of incident response, the system is trained to recognise 12 distinct incident events (such as jaywalking or hit-and-runs): perpetrators are identified using number plate recognition technology and, increasingly, visual recognition. More than 2500 incidents are reported daily by City Brain, with a reported $95 \%$ accuracy rate. The real-time capability of the system is exemplified by the fact that City Brain can process over $16 \mathrm{~h}$ of video from different camera sources within $60 \mathrm{~s}$ (Alibaba Cloud 2018).

It is key to note that the measures of success are, like the platform's focus, limited in terms of scope and time horizon. With regards to scope, the corporation's celebration of success is related to assessing whether the system works in terms of its components and subsystems. Additionally, the measures of success used in promotional and corporate documentation are highly technical and related to themes of efficiency, speed of analysis, automation, and other key descriptors normally associated with corporate logics promoting the smart city. Notwithstanding corporate celebrations of success, it is to be expected that a highly technical system such as City Brain would experience issues with its automated application. For example, a taxi driver we interviewed claimed that the automated system for detecting traffic and other infractions sometimes interpreted individual behaviour incorrectly. They related that issues like this are: almost inevitable as Hangzhou promotes 'being polite to the passengers' and if a camera catches someone walking around my car at a certain point, it defines me as 'rude' to the passenger and I would lose 3 points [from their driving licence] and pay a $100 \mathrm{RMB}$ fine.

Regarding time horizon, the platform's success is clearly described as being assessed in an operational timeframe comprising days or weeks. What is lacking from discussions of success are measures that inform as to the broader impact, relevance and benefit of the system in economic, social, and cultural terms. Although it is not surprising that corporate discourse about a specific product should be described in circumscribed terms, as with City Brain, at the same time it is key to maintain a critical distance from advertised and promoted notions of an urban platform having gained rapid 'success' in transforming the city.

The stated experimental success of Hangzhou City Brain is important because it justifies its increasing adoption in other cities. Our interviews indicated that by the end of 2018, City Brain had been exported to, and implemented in 15 other Chinese cities, and in Kuala Lumpur. Concurrently, the Hangzhou version of City Brain remains experimental due to constant testing of upgrades to the city's system. This includes the trialling of more advanced analytics capabilities, as well as hardware upgrades including AI traffic lights. This has necessitated not only collaboration between Alibaba and the city government, but also the assemblage of a technological development network including security corporations Hikvision and Dahua. Our research showed awareness of the multiple systems in play in the city, as seen in the following excerpt from an interview with a member of the traffic police department:

The AI traffic lights use the same level calculating power as Alpha $\mathrm{Go}^{1}$, it adjusts traffic lights through real-time analysis of traffic flows. City Brain 2.0 is more advanced than 1.0, particularly in the application of AI technologies.

\footnotetext{
${ }^{1}$ A Google DeepMind AI program that plays the Go board game.
} 


\section{Platforming and experimenting with the Chinese smart city}

In analysing the City Brain case, we draw on two distinct literatures, on platform urbanism and the experimental city. We identify two cross-cutting themes that apply across both literatures, and that can also be used as analytical lenses through which the empirical case of City Brain can be studied. While a full outline of both sets of literature lies outside the scope of this paper, it is nonetheless useful to contextualise them here, before focusing on shared themes.

Firstly, our analysis of City Brain as a smart city project is based within a recent research focus on the evolution from smart to digital platform-based cities (Ansell and Miura 2019). Scholars increasingly argue that while the smart city, as defined above, is becoming paradigmatic as an urban development discourse (Joss et al. 2019), we are seeing an evolution of smart urbanism towards what has been called platform urbanism (Han and Hawken 2018). While the definition of urban platforms is still being debated, platform urbanism can be genealogically traced to work on platform capitalism (Srnicek 2016). This argues that capitalism has evolved so that the platform, understood as 'a distinct mode of socio-technical intermediary and business arrangement that is incorporated into a wider process of capitalisation' (Langley and Leyshon 2017, p 11), has become the central organizing interface in the digital economy and beyond (Benghozi and Paris 2016; Rossi 2020). Discursively, the platform 'now conveys an ideological imaginary associated with the reconfiguration of production, consumption, distribution and monetization of cultural goods and services' (van der Graaf 2018, p 153).

At the same time, and concurrent with the development of the smart city, urban platforms have risen to prominence. As Murakami Wood and Mackinnon (2019, p 177) argue, 'It is no coincidence that many of the entities that promote smart cities are US platform corporations, organisations that have built their success on being the underpinning technology, or the infrastructure, for many other activities.' Although urban platforms are active across a spectrum of stakeholders, from the corporate sector (Uber, Airbnb, Taobao), to governance (such as city dashboards), their defining characteristic is that they are the interfaces through which the smart city increasingly makes sense of, orders, and commodifies the 'data exhaust of our cities' that is 'of increasing value to governments and businesses as they seek to apply data-driven methodologies to improve the quality and efficiency of city services' (Barns 2018: 5; see also Ye and He 2016). Platforms such as City Brain are examples of the shift from smart urbanism, with its focus on Big Data analytics and centralized digital governance systems, and towards a form of urbanism that, while not excluding other aspects of the smart city, places platforms (which may or may not be specific to a particular city) at the centre of the urban (governance, consumption, regulatory, etc.) experience (Lin 2019; Rose et al. 2020).

A second body of research on which we draw focuses on the experimental city. City Brain can be conceptualised as an experimental product being trialled, initially at least, in a specific city that is in itself seen as an experimental site. Literature on urban experimentation has, over the past decade, highlighted how cities can be seen as sites of urban technical, political, policy and social experimentation focused on a wide range of issues from sustainability, to climate change, energy transitions, experimental modelling and digital transformations (Castán Broto and Bulkeley 2013; Clarke 2013; Cugurullo 2018; Evans et al. 2016; Torrens et al. 2018). While delving into this broad literature lies outside the scope of this paper (but see Evans 2016), the ways in which our study of City Brain connects with, and contributes to, this area of research is two-fold. Firstly, in analysing the development of technological, urban futures-focused 'solutions' for Chinese smart cities, we underline a developing view, in China, of the city as a place of experimentation. In part, this continues a decades-long trajectory of economic and urban experimentation promoted and managed by the Chinese state since the start of the reform era (late 1970s) and which is exemplified by the multiplication of Special Economic Zones (SEZ) (Yeung et al. 2009) and associated boom towns-turned-megacities such as Shenzhen. However, while previous urban experimentation was mostly focused on economic reform, smart city projects are evidence of a shift in approach, whereby the city comes to be seen as a specific place for the testing of new techno-social approaches for steering urban processes (Karvonen et al. 2018). This can be seen by the testing, in Hangzhou, of City Brain version 1.0 
(from 2016) to 3.0 (from 2020). Secondly, the city itself becomes seen as experimental because of its generative and responsive nature: generative because it is the environment through which data is generated and from which it sourced, and responsive because the digital platform can be used to nudge urban flows (from transport, to emergency response, to consumption behaviours) through direct action on the city (whether through smart traffic lights, data feeds into smartphones, or other means). In the remainder we consider the case of City Brain as an example of the rise of the platform in urban China as an urban experiment that is both relationally co-produced and spatially contingent. Both themes can, we argue, be applied across literature on platform urbanism and the experimental city.

\section{Relational co-production of the platform city}

The city and its infrastructures, projects, flows, and cultures can be understood as both relational and coproduced. Our understanding of relationality is based on a heterogeneous body of literature that has sought to understand economic, geopolitical and cultural processes as constructed through mechanisms of negotiation, debate and argumentation that place relations and performances between actors at centre stage (Jessop and Sum 2018). The city, then, becomes a malleable 'thing' that is the ever-evolving product of interactions not only between actors, but between different actors' understanding(s) of the same processes and urban realities (Gualini and Fricke 2019). These interactions, in turn, are involved in processes of co-production. These can be considered both central to the territorialisation of specific urban platforms (because of their synergistic elements, which can be expressed at the local level through specific strategies, products or forms of service delivery), and to the treatment of urban platforms as experimental. Thus, a focus on City Brain as an experimental platform developed and tested in Hangzhou as a laboratory highlights the linkages between literatures on coproduction and on experimental urbanism (Chatterton et al. 2018). However, while most of the literature on co-production in urban planning, design and implementation in Western contexts describes a key element of the co-production process as openness to citizen input (Bartenberger and Sezściło 2016; Voorberg et al. 2015), in the Chinese case this is limited due to the specific context of China's urban management system. Rather, the synergistic elements of co-production in China's smart urban landscape lie in the interaction between corporate and state actors at multiple scales. In urban China, therefore, co-production can be defined less as involving citizens in synergistic processes of service delivery and consumption, and more as the involvement of non-state actors, and of municipal authorities, in translating policy directives to a local context while co-designing and co-implementing smart urban platforms.

Our conceptual approach considers City Brain to be relational as well as co-produced. We draw on the relationality and co-production literature because of the potential it affords to interpret the city as a complex and dynamic construct that is materially, discursively, informationally and affectively co-constituted. A relational lens enables empirical work to be distanced from an agentially-unidirectional view of the urban, where the city is seen and described as the result of a series of targeted interventions carried out by specific actors on the substrate of the city.

The territorialisation of platform-based urban experiments

The second theme explored in this paper is that of the importance of geographies of scale and place in the materialisation of Chinese smart cities. We argued, above, that in the case of City Brain, the city can be considered both a laboratory and a field site. Cities can be seen as key sites of material specificity and spatial contingency, and as sites of translation of policy objectives 'from above' into local priorities, budget and resource allocations, and strategic urban development directions. The co-production of City Brain by both corporate and governmental actors can thus be interpreted through a conceptual lens that highlights the key agency of cities (understood as networks of actors) themselves.

The first element of territorialisation that we focus on is the key interaction between corporate and state stakeholders in producing City Brain in specific geographies. The central involvement of Alibaba adds to an understanding of the emergence of Chinese smart cities because of its key role in shaping city-specific urban policy and management. Alibaba is not simply one of several 'influences from elsewhere' (Robinson 2015, p 831), but a central enabling actor without 
whom Hangzhou's City Brain platform would not exist. In part, this confirms findings underlining the predominance of corporate power and visions in smart city development (Hollands 2015; Wiig 2015; Sadowski and Bendor 2019). At the same time, the City Brain case extends this because of the complex power geometries between city authorities and technology corporates (Bunders and Varró 2019). We wish to avoid presenting a straightforward narrative of corporate power normatively 'parachuting' smart city products into the city with little regard for geographical specificity, a point made in recent studies (Cowley and Caprotti 2019). City Brain shows that space and local context matter in the smart city (Karvonen et al. 2018), as do interactions between corporate and governmental actors. Thus, while City Brain is a high-tech digital platform that, on the surface at least, is concerned with real-time Big Data and AI urban management applications, it is also (because of its imbrication within specific, multiple urban polities) an example of a deeply spatial process of transfer (van der Heijden 2016), over space, of a particular approach to city management.

The second element of territorialisation that we leverage to analyse City Brain as an experimental urban platform is drawn from studies of architecture and urban design that point to the physical, geographically-specific elements of territorialisation processes (Kärrholm 2012), and to the importance of the local context as a way of negotiating smart and platform city products and policies that may, under close inspection, display significant local diversity, as shown in studies of the territorialisation of smart city discourses and strategies in the UK (Caprotti and Cowley 2019). Based on this, we aim to show how cities that develop smart and urban platform projects "might become home to assemblages whose constitutive parts are homogeneously drawn from a smart city repertoire made up of discourses and material elements' (Parks and Rohracher 2019, p 53), whilst these self-same elements and discourses become locally-determined through geographical contingency. In the case of City Brain, the set of global smart city discourses in which Alibaba's agency can be situated are translated into a contingent context specific to Hangzhou-and, eventually, to other cities in China and internationally that have adopted the City Brain platform. This element of territorialisation functions to ground and root urban platforms. At the same time, we recognise that the scalability of platforms, and their spread to other urban and national contexts, also constitutes an element of deterritorialization that goes hand in hand with processes of deep territorialisation.

\section{Co-producing the relational Chinese smart city}

City Brain is an example of a smart urban platform that is not unidirectionally foisted onto a city administration. This understanding helps move past a view of the smart city as developed and deployed by corporations onto the city, with the urban seen as a passive substrate without significant agency. Rather, the development of City Brain shows a clearly relational process that brought into play multiple actor typologies at a range of scales.

While Alibaba is City Brain's main corporate stakeholder, the project involves several state actors, including the Hangzhou city administration. Other companies are involved in City Brain but often have strong state links. Hikvision, for example, supplies surveillance cameras for use by the platform, and is more than $40 \%$ owned by State-Owned Enterprises (SOEs) (Honovich 2015). This means that while the Chinese government does not directly control the City Brain project, it retains leverage over it through both the Hangzhou city administration, and corporations involved in it. The overall context, then, is of smart city projects initiated by state or local administrations, with corporate actors such as the BATH corporations attempting to develop niches within the broader, national policy landscape (Simmons et al. 2018). These niches are often technology-specific. As a Tencent executive stated, 'Alibaba focuses on transportation: we also do transportation, but we have less AI application. We are mainly focused on healthcare.' Our research has not focused on the technological specialisation of different BATH actors in varied urban experimental sites. However, it can be argued that City Brain is an example of a platform that is relationally envisioned and produced, and that was developed in highly specific ways at the city level, while other corporations developed approaches relevant to other (non-transportation) sectors in other cities throughout the Chinese urban landscape.

Another relational facet to the development of City Brain was the transformation of some branches of city government in order to interface with corporations, 
and other stakeholders active in the flow and interchange of data. This is a facet of relational coproduction that is captured by the concept of malleability (Gualini and Fricke 2019). This is exemplified within Hangzhou by the setting up of a Bureau of Data Resource, founded in 2017 so as to enable the city to better standardise its approach to the use of digital data in urban services, and to maximise the utility of data gathered from platforms such as City Brain. An executive working with the Hangzhou Citizen Card Company noted that the 'logic' behind the Bureau of Data Resource was based on 'facilitation of the digitalization of the city. This dramatic institutional change is nothing new, it is part of the experiment for more efficient digitalization.' Therefore, City Brain 1.0 (and subsequent iterations) made change necessary in city government interfaces with data-focused stakeholders. This points to the view not only of City Brain, but of the city as a whole (including its governance organizational structure) as an experimental laboratory where smart urban trajectories can be tested, and that is relational at its core. In this sense, relationality, and the dynamic interactions that helped shape Hangzhou smart city, was the core part of the City Brain experiment.

Hangzhou-specific priorities were also fed into the City Brain development process by city departments, including the transportation department, which was centrally involved in the design requirements. An official working for the department stated that seven department employees were involved in City Brain design, because:

'the design needs to meet the requirements of the transportation department. Many figures and indices are requested by users and then materialized by Alibaba. Our leader told us the software and technologies should feed our demands, rather than letting the software tell us how to design it.'

Again, this points to the relational co-production of City Brain as a corporate-state project rather than as a simple narrative of corporate-led development of the smart city. The focus on city-specific priorities leads us to the next facet that applies to City Brain as both co-produced and experimental: its territorialisation.

\section{Territorialising City Brain: geographies of data- centred urbanism}

The adoption of City Brain by Hangzhou and, subsequently, other Chinese cities (Min et al. 2018), is part of the increasing use of real-time data analytics for urban management and regulation (Kitchin 2014). Concurrently, as seen above, City Brain is rooted in a network of co-production contingent on the specific geography of each city where the platform is to be rolled out, and that is a key component in processes of territorialisation of the smart city (Kärrholm 2008). This spatial specificity is largely tied to local economic and urban development priorities. In Hangzhou, our interviewees repeatedly linked City Brain with local political-economic imperatives, namely the stimulation of a new urban economy focused on digital technologies and data analytics. As an interviewee noted, 'The initiation of City Brain is also a way of supporting the local digital economy, which Hangzhou government invested in.' The same interviewee recognised that while City Brain was initially developed in relation to Hangzhou and its design requirements, at the same time the product could be sold to other cities: 'Then what else they [Alibaba] do is up to them, as in how many deals they can get from other cities.' One interviewee, working for the Hangzhou transport department, noted that more than 70 mayors had visited their department and that this was interpreted as interest in urban management technologies.

Local economic and political priorities thus justified the development of City Brain. Notwithstanding City Brain's origin and continued status as an experimental system undergoing constant development and upgrading from versions 1.0 through to the current version 3.0, city administrators were keen to point out that the development of the digital platform was part of a geographically-specific process of economic and spatial prioritisation of key industrial activities by the city government. In this sense, experimental smart platform urbanism was purposive (Levenda 2018), conceived as a way of achieving broader socioeconomic goals. For example, a city official interviewed for this research pointed out the key role of the city's mayor, Guoping Wang, and the establishment of an urban economic vision focused on digital technologies and innovation. This can be seen both by Alibaba's presence in the city (Miao et al. 2019), and 
by the strategy of establishing technology spin-off companies from Zhejiang University, one of the country's top five research institutions. As the official emphasized: 'Projects like City Brain emerged from such a background', emphasising the Hangzhou urban administrative landscape. At the same time, broader state steering was clearly acknowledged, with a Hangzhou Citizen Card Company employee stating that 'the government has governance needs, tech firms are filling the gap.' Another interviewee, working for a technology corporation, told us:

You need to understand, it [the development of City Brain] is what the state wanted. It is the same logic behind rapid urbanization in China.

Therefore, City Brain is an example of urban development that is experimental and both state-led and market-oriented, and represents a territorialisation of local government economic agendas (Wu 2002).

While the state is sometimes seen as the direct stimulator of experimental city projects, our research points to the fact that it is also at times perceived as an inhibitor or as a selective agent. For example, while Alibaba was able to develop City Brain in Hangzhou, at the same time the city was not the experimental site selected for the trial of another key smart urban product, namely digital IDs. According to one interviewee at the Hangzhou Bureau of Data Resource:

Current smart cities construction is at a stage of 'let a hundred flowers blossom and a hundred schools of thought contend', Hangzhou and Guangzhou are competing to become the model for smart cities in China and lead the smart industry [...]. A lot of the time it is not because the technology doesn't allow us to do things but because the state doesn't permit it. Hangzhou attempted to launch digital ID but Guangzhou got the permit from the state.

Thus, a key determinant of the territorialisation of smart city products such as City Brain seems to be the strategic appointment, by central and provincial governments, of specific model cities for certain types of economic development, such as the digital economy. Model cities function as experimental sites, and as urban laboratories where specific approaches and technologies can be tested. Thus, there is a national geography of experimental urban sites for promoting the emergence of digital and platform urbanism.
Table 1, for example, shows the cities and provinces where some of the major Chinese smart city corporations (Ping An, Alibaba, Tencent and Huawei) are actively trialling their products. ${ }^{2}$

\section{Discussion and conclusion}

In this paper, we have focused on the co-production and experimental deployment of the City Brain smart urban platform as a way of analysing how Chinese platform urbanism is both relational and territorialised in specific ways. The remainder of the paper offers several points of discussion and concludes with a call for an expanded research focus on experimental, digitally-enhanced urbanism in China.

Firstly, our research shows that products such as City Brain exhibit varying degrees of territorialisation at several scales. City Brain was territorialised both in Hangzhou, and by the relational co-production of the platform in a specific urban context. Thus, it is an example of the ways that digital urban platforms are not imposed onto city administrations but are relationally co-constituted by networks of actors. These actors, ranging from state and provincial government officials, to corporate executives, to local authorities (such as traffic departments), have a stake in the specific contextualisation and design of a complex digital product such as City Brain. In this context, Hangzhou was a highly specific and contingent setting for experimental smart platform urbanism. Its specific configuration in the national landscape, its connection to national digital economy agendas, and its highly localised configuration of relationality between city government and technology firms such as Alibaba was key to performing City Brain.

At the same time, the same mechanisms which enabled City Brain to be developed and trialled as an experiment in Hangzhou also dynamically change so as to be context-specific in other cities within and outside China, from Chongqing to Kuala Lumpur and in between. An example of this is the announcement,

\footnotetext{
${ }^{2}$ Ping An was selected for the table over Baidu due to the number of projects throughout China. Additionally, Tencent and Huawei claim that they are trialling smart urban products in over 35 and 48 cities respectively, but the cities on the table are the ones on which information was found in the context of research presented in this paper.
} 
Table 1 Some cities and provinces in which four Chinese technology corporations are trialling smart city projects

\begin{tabular}{lllll}
\hline & Pingan & Alibaba & Tencent & Huawei \\
\hline City & Guangzhou & Hangzhou & Guangzhou & Beijing \\
Shenzhen & Suzhou & Shenzhen & Shenzhen \\
Shanghai & Shanghai & Shanghai & Shanghai \\
Changsha & Guangzhou & Huangshi & Tianjin \\
Nanning & Quzhou & Tianjin & Weifang \\
Wuhan & Fuzhou & Changsha & Yiyang \\
Nantong & Haikou & Henan Province & Guilin \\
Chuzhou & Chonqing & Hainan Province & Sanya \\
Zhaoqing & Tongxiang & Sichuan Province & Dunhuang \\
& Macao & Guizhou Province & Gaoqing \\
& Kuala Lumpur & Hubei Province & Hengtai \\
& & Shanxi Province & Shenzhen \\
& & & Shijiazhuang \\
& & &
\end{tabular}

in January 2018, that the Malaysia Digital Economy Corporation (MDEC) (a government-owned institution responsible for running Malaysia's Multimedia Super Corridor) and the Kuala Lumpur City Government had selected City Brain for roll-out in the country's capital. However, the City Brain product was adapted to the specifications laid out by the two Malaysian institutions, which requested that Kuala Lumpur's City Brain be focused exclusively on traffic management, urban planning, and the environment (Gao and Mak 2018; Zhang et al. 2019). Again, this highlights the geographical contingency, relationality and co-production that contributed to the materialisation of City Brain outside Hangzhou.

Analysis of the co-production of digital urban platforms such as City Brain helps to extend current critiques of digital and smart urbanism that have tended to focus on examples of corporate-led products being applied within cities with little participation from local city governments. It is clear, in the Chinese case, that city governments (and authorities at various scales) are key actors in the formation of digital urbanism; at the same time, their role is a negotiated one due to the imbalances in technical and R\&D know-how between the corporate and state spheres. It is therefore key to consider the dynamic interrelationship, and associated strengths and weaknesses, of both corporate and government spheres in smart and platform urbanism.

Secondly, territorialisation went hand in hand with experimentation. City Brain responded, from its first iteration, to the needs and requirements of Hangzhou as the first urban site where the platform was to be trialled. Hangzhou effectively functioned as both a laboratory, and as a field site (Evans 2016). The city was, essentially, a controlled environment where City Brain could be tested, assessed, modified and (if circumstances warranted) halted. It is in this sense that it can be understood as a laboratory. Nonetheless, as a system reliant on Big Data, City Brain was also predicated on the treatment of Hangzhou as a field site, from where data, and the reality of urban life, could be analysed and eventually partially steered. Concurrently, experimental success could then justify the marketing of the City Brain product to other Chinese cities, and abroad: this is where urban experimentation connects not just with the broader adoption of innovation, but with the material processes of territorialisation of the smart city.

This leads to a third reflection, focused on the fact that locality was part of the founding driver for a product that was eventually meant to be widely sold to other urban jurisdictions. This points to the importance of local urban context in co-producing digital urban platforms and other smart urban systems. City Brain was a negotiated platform that, because of its coproduction by state and corporate actors, was firmly rooted in a specific city context. Furthermore, the importance of the local, specific urban context was not only confined to Hangzhou City Brain, but was crucial in the marketing of the platform, and its adoption, by other cities in China and abroad. This finding extends current knowledge on smart city products, by highlighting the importance of a co-produced local urban 
context in the development of smart cities. While much of the literature has been criticised for its aspatial focus, the City Brain example highlights the importance of a complex pattern of local priorities and urban contexts in the development of data-enabled urbanism.

Fourth, the relational perspective is a particularly useful contribution to studies of the Chinese smart city. This is because a potential bias in this paper is that of reifying key state and corporate actors, with recourse to oft-repeated tropes that stereotype Chinese urban and political development as hegemonic (Wang 2019). Rather, we argue, the Chinese smart and platform city can be seen as the result of a more dynamic, relational process involving multiple state, corporate, and hybrid actors in the co-production of projects that may be represented as stable, but that are by no means monolithic or not open to change. At the same time, focusing on a relational, co-produced view of the city allows for a potential sidestepping of the instrumental, paternalistic and pragmatic views of the smart city, and for the opening up of a space for debate of ideals beyond techno-economic and other imperatives (Cardullo and Kitchin 2019).

Our discussion has focused on relationality between actors with clear agency in developing and deploying urban platforms and the broader smart city, sometimes employing 'black box' mechanisms that shield urban development strategies from critical engagement. We describe smart and platform projects as 'black boxes' as they are often designed, proposed and authorised by networks of elite techno-economic and policy actors, while urban citizens effectively remain outside the 'black box'. It is true, however, that some of the experience of the smart and platform city is accessible by urban dwellers through smartphones, apps, and other platform devices. It is key to critically debate the digital economies and social networking interactions available in the platform city. At the same time, these interactions represent relationality in the sense of potentially positive interconnectedness between citizens: 'a differently constructed urban sociality, where no one is alone, and each person is connected to social networks both formal and informal' (Lejano 2019, p 26). The progressive potential, and dystopian gateways, offered through such a view of the relational platform city are becoming clear (Allam et al. 2019). Here, we underline the fact that experimenting with relational and co-produced urban platform projects carries with it the key socio-political and ideological responsibilities (and consequences) of enmeshing specific, diverse types of relationality into the urban fabric.

Fifth, while our paper was not a comparative study in empirical terms, some of our findings can be generalizable outside the Chinese urban context. While the way in which City Brain was developed in Hangzhou was clearly contingent on the specific urban setting within which the project emerged, at the same time it can be argued that the design of future urban digital strategies and projects needs to be considered at the same time as local context. Furthermore, although the ways in which relationality, co-production and territorialisation may work outside Hangzhou (and indeed outside China) may differ, the paper offers a framework for considering the materialisation of platform urbanism by focusing on these three key factors. This is because it is apparent that it is the interaction between these aspects that helps to materialise the future digital city, although its shape may differ depending on geographical contingency.

Finally, our study points to three pathways for future research. Based on our exploration of territorialisation above, our first direction for future research is focused on the scale and granularity of enquiry into the platform city. As Gardner and Hespanhol (2018) have argued, while the metropolis and community are key scales at which smart city projects are operationalised, the individual dimension also needs to be considered. Indeed, it is at the level of the individual, and of the personalisation of the smart and platform city experience, that future research could begin to engage with the way(s) in which digitally-mediated cities construct specific notions of urban citizenship. It is clear that platforms such as City Brain perform citizens as participants in an urban experiment through their provision of data, patterns of (economic, transport, and other) activity, and response to governance inputs (through, for example, smart citizen cards and apps). A key question, then, is the extent to which integration of the citizen into these systems (through smartphone interfaces and other products, including wearable and health technologies) changes what it means to be a citizen in the data-enabled city.

Secondly, and building on the above, there is ample scope for researching the role of the urban citizen in the new platform city, in China and beyond. This point is based on the absence, rather than presence, of 
citizens from the planning of many smart urban development projects globally. In the specific case of City Brain, it could be argued that citizens were, to some extent, silent in the process of experimental coproduction. Indeed, in the case of Hangzhou, citizens seemed to mostly be involved not in negotiating the design and application of the platform, but in performing a part, mostly unwittingly, as experimental subjects, according to what has been termed a 'user as test bed' model (Levenda 2019). Without citizens on which the various technologies could be trialled, and without citizens on whom sensor systems were reliant for (mostly passive) data inputs, the City Brain experiment would have remained static and unanimated. The smart urban platform was, indeed, made dynamic and enabled to function in real time through the everyday, ordinary activities of individual citizens, through smartphones, transport routines, and other forms of sensed and quantifiable behaviour. At the same time, citizens themselves seemed to possess little agency in informing platform operators, or in affecting City Brain in other constructive ways.

Thirdly, the paper's focus on digital governance of the contemporary city leads to questions around the implications of smart and platform technology on urban life. Scholars have sounded a note of caution about the potential effects, on the public sphere and the urban commons, about the impact of platform urbanism on today's cities. Rossi (2019, p 12), for example, argues that 'today's platform metropolis is bound to become a key site of confrontation between high-tech corporations and subaltern subjectivities reclaiming their part in the redistribution of socially produced wealth.' It is too early to tell whether this prediction will come true in the Chinese city, but there are currently few indications of platform-triggered confrontation and contestation happening to date in China. While there are clear security and surveillance aspects to smart urban platforms such as City Brain, the application of the technology package has not, so far, been overtly oppressive. Rather, our work confirms findings from smart city research outside China (Cowley et al. 2018), that point to smart city projects generally serving to define urban citizens as either service users, or as entrepreneurial agents in the digitally-enhanced economy. At the same time, firms themselves are signalling a potential change not in the use of technology for surveillance, but in the ways in which intelligent systems will influence social and urban life (Leszczynski 2016). As Tian Feng, director of Alibaba Cloud research, argued in a presentation, both spheres of human and artificial intelligence are a 'known world', while the emerging sphere of 'machine intelligence' (which we would argue includes autonomous systems such as those that are part of City Brain) is an 'unknown world' (Feng 2018). This points to the fact that the smart city of the near future, in China as elsewhere, is in large part an unknown factor at the same time as its contours are defined by narratives that anticipate the urban future in many (often exclusionary) ways (Jazeel 2015). Based on the above, we conclude with a call for critical engagement with emerging smart, digital platform urbanism in China and elsewhere.

Acknowledgements This work was supported by the Economic and Social Research Council [grant number ES/ L015978/2]. We are grateful to Angeliki Balayannis for valuable comments on an earlier draft of this paper.

Funding This work was supported by the Economic and Social Research Council [grant number ES/L015978/2].

\section{Compliance with ethical standards}

Conflicts of interest All authors declare that they have no conflict of interest.

Availability of data and material (data transparency) Data is available through the UK Data Service (UKDS): https://beta. ukdataservice.ac.uk/datacatalogue/studies/study?id=853646

\section{References}

Alibaba Cloud. (2018). ET City Brain. Available at: https:// uploads-ssl.webflow.com/5b20fdf071061967d188a98e/ 5bb693e27653212ece95077d_Alibaba\%20Cloud\% 20ET\%20City\%20Brain_28.09.2018\%20Riga.pdf (2019).

Allam, Z., \& Dhunny, Z. A. (2019). On big data, artificial intelligence and smart cities. Cities, 89, 80-91. https://doi. org/10.1016/j.cities.2019.01.032

Ansell, C., \& Miura, S. (2019). Can the power of platforms be harnessed for governance? Public Administration. https:// doi.org/10.1111/padm.12636

Atha, K., Callahan, J., Chen, J., Drun, J., Green, K., Lafferty, B., McReynolds, J., Mulvenon, J., Rosen, B., Walz, E. (2020) China's Smart Cities Development. SOSi. https://www. uscc.gov/sites/default/files/2020-04/China_Smart_Cities_ Development.pdf

Barns, S. (2018) Smart cities and urban data platforms: designing interfaces for smart governance. City, Culture and Society, 12, 5-12. https://doi.org/10.1016/j.ccs.2017. 09.006 
Bartenberger, M., \& Sezściło, D. (2016). The benefits and risks of experimental co-production: the case of urban redesign in Vienna. Public Administration, 94(2), 509-525. https:// doi.org/10.1111/padm.12233

Battaglini, E., Horlings, L., \& Dessein, J. (2016). Territorialisation, a challenging concept for framing regional development. In R. Dessein, E. Battaglini, \& L. Horlings (Eds.), Cultural Sustainability and Regional Development (pp. 249-259). London: Routledge.

Benghozi, P.-J., \& Paris, T. (2016). The cultural economy in the digital age: a revolution in intermediation? City, Culture and Society, 7(2), 75-80. https://doi.org/10.1016/j.ccs. 2015.12.005

Bulkeley, H., \& Castán Broto, V. (2013). Government by experiment? Global cities and the governing of climate change. Transactions of the institute of British Geographers, 38(3), 361-375. https://doi.org/10.1111/j.14755661.2012.00535.x

Bunders, D. J., \& Varró, K. (2019). Problematizing data-driven urban practices: insights from five Dutch 'smart cities.' Cities, 91, 145-152. https://doi.org/10.1016/j.cities.2019. 05.004

Caprotti, F., \& Cowley, R. (2019). Varieties of smart urbanism in the UK: discursive logics, the state and local urban context. Transactions of the Institute of British Geographers. https://doi.org/10.1111/tran.12284

Caprotti, F., \& Liu, D. (2020). Emerging platform urbanism in China: reconfigurations of data, citizenship and materialities. Technological Forecasting and Social Change, 151(February 2020), 119690. https://doi.org/10.1016/j. techfore.2019.06.016

Caprotti, F., Springer, C. H., \& Harmer, N. (2015). 'Eco' for whom? Envisioning eco-urbanism in the Sino-Singapore Tianjin Eco-City, China. International Journal of Urban and Regional Research, 39(3), 495-517. https://doi.org/10. $1111 / 1468-2427.12233$

Cardullo, P., \& Kitchin, R. (2019). Smart urbanism and smart citizenship: the neoliberal logic of 'citizen-focused' smart cities in Europe. Environment and Planning C: Politics and Space, 37(5), 813-830. https://doi.org/10.1177/ $0263774 X 18806508$

Chatterton, P., Owen, A., Cutter, J., Dymski, G., \& Unsworth, R. (2018). Recasting urban governance through Leeds City Lab: developing alternatives to neoliberal urban austerity in co-production laboratories. International Journal of Urban and Regional Research, 42(2), 226-243. https://doi. org/10.1111/1468-2427.12607

Clarke, K. C. (2013). Why simulate cities? GeoJournal, 79, 129-136. https://doi.org/10.1007/s10708-013-9499-5

Cossetta, A., \& Palumbo, M. (2014). The co-production of social innovation: the case of living lab. In R. P. Dameri \& C. Rosenthal-Sabroux (Eds.), Smart City: How to Create Public and Economic Value with High Technology in Urban Space (pp. 221-235). Berlin: Springer.

Cowley, R., Caprotti, F. (2019) Smart city as anti-planning in the UK. Environment and Planning D: Society and Space, 37(3), 428-448. $\quad$ org/https://doi.org/10.1177/ 0263775818787506

Cowley, R., Joss, S., \& Dayot, Y. (2018). The Smart City and its publics: insights from across six UK cities. Urban
Research \& Practice, 11(1), 53-77. https://doi.org/10. 1080/17535069.2017.1293150

Cugurullo, F. (2018) Exposing smart cities and eco-cities: Frankenstein urbanism and the sustainability challenges of the experimental city. Environment and Planning A: Economy and Space 50(1): 73-92. https://doi.org/10.1177/ 0308518X17738535

de Jong, M., Wang, D., Yu, C. (2013) Exploring the relevance of the eco-city concept in China: The case of Shenzhen SinoDutch low carbon city. Journal of Urban Technology, 20(1), 95-113.

Empson, L. (2018). Elite interviewing in professional organizations. Journal of Professions and Organization, 5(1), 58-69. https://doi.org/10.1093/jpo/jox010

Evans, J. (2016). Trials and tribulations: problematizing the city through/as urban experimentation. Geography Compass, 10(10), 429-443. https://doi.org/10.1111/gec3.12280

Evans, J. (2011). Resilience, ecology and adaptation in the experimental city. Transactions of the Institute of British Geographers, 36(2), 223-237. https://doi.org/10.1111/j. 1475-5661.2010.00420.x

Evans, J., Karvonen, A., \& Raven, R. (2016). The experimental city: New modes and prospects of urban transformation. In J. Evans, A. Karvonen, \& R. Raven (Eds.), The Experimental City (pp. 1-12). London: Routledge.

Feng, T. (2018). Inclusive technology change the world. Available at: https://www.unescap.org/sites/default/files/ 2_Alibaba.pdf (2019).

Gaffney, C., \& Robertson, C. (2018). Smarter than smart: Rio de Janeiro's flawed emergence as a smart city. Journal of Urban Technology, 25(3), 47-64. https://doi.org/10.1080/ 10630732.2015.1102423

Gao, F., \& Mak, L. (2018) Alibaba Cloud launches Malaysia City Brain to enhance city management. Alibaba Cloud press release, 29 January 2018. https://www.alibabacloud. com/press-room/alibaba-cloud-launches-malaysia-citybrain-to-enhance-city-management

Gardner, N., \& Hespanhol, L. (2018). SMLXL: Scaling the smart city, from metropolis to individual. City, Culture and Society, 12, 54-61. https://doi.org/10.1016/j.ccs.2017.06. 006

Gualini, A., \& Fricke, G. (2019) 'Who governs' Berlin's metropolitan region? The strategic-relational construction of metropolitan scale in Berlin-Brandenburg's economic development policies. Environment and Planning C: Politics and Space, 37(1), 59-80. https://doi.org/10.1177/ 2399654418776549

Han, H., \& Hawken, S. (2018). Introduction: innovation and identity in next-generation smart cities. City, Culture and Society, 12, 1-4. https://doi.org/10.1016/j.ccs.2017.12.003

Hangzhou City website (2020). City Brain 3.0 is officially released, using brain power to enhance 'city immunity'. https://hznews.hangzhou.com.cn/chengshi/content/202006/10/content_7752342.htm

Hollands, R. G. (2015). Critical interventions into the corporate smart city. Cambridge Journal of Regions, Economy and Society, 8(1), 61-77. https://doi.org/10.1093/cjres/rsu011

Hong, Y. (2017). Networking China: The Digital Transformation of the Chinese Economy. Champaign, IL: University of Illinois Press. 
Honovich, J. (2015). Hikvision and the Chinese government. Available at: https://ipvm.com/reports/heres-what-reallysets-hikvision-apart (2019).

Hsu, J. W. (2018). Alibaba cloud launched 'ET city brain 2.0' in Hangzhou . Available at: https://www.alizila.com/alibabacloud-launched-city-brain-2-0-hangzhou/ (2019).

Hu, S. (2018). Digitalization: Alibaba Cloud's stories. Available at: https://www.big-data.ai/sites/default/files/Big_Data. AI_Summit-Hu.pdf (2019).

Jazeel, T. (2015). Utopian urbanism and representational cityness: on the Dholera before Dholera smart city. Dialogues in Human Geography, 5(1), 27-30. https://doi.org/10. $1177 / 2043820614565866$

Jessop, B., Sum, N.-L. (2018) Geopolitics: putting geopolitics in its place in cultural political economy. Environment and Planning A: Economy and Space, 50(2), 474-478. https:// doi.org/10.1177/0308518X17731106

Jia, K., Kenney, M., \& Zysman, J. (2018). Global competitors? Mapping the internationalization strategies of Chinese digital platform firms. In R. van Tulder, A. Verbeke, \& L. Piscitello (Eds.), International Business in the Information and Digital Age (pp. 187-215). Emerald Publishing Limited: Bingley.

Joss, S., Sengers, F., Schraven, F., Caprotti, F., \& Dayot, Y. (2019). The smart city as global discourse: storylines and critical junctures across 27 cities. Journal of Urban Technology, 26(1), 3-34. https://doi.org/10.1080/10630732. 2018.1558387

Kärrholm, M. (2012). Retailising Space: Architecture. Farnham, Ashgate: Retail and the Territorialisation of Public Space.

Kärrholm, M. (2008). The territorialisation of a pedestrian precinct in Malmö: materialities in the commercialisation of public space. Urban Studies 45(9): 1903-1924. https:// doi.org/10.1177/0042098008093383

Karvonen, A., Cugurullo, F., \& Caprotti, F. (2018). Introduction: situating smart cities. In A. Karvonen, F. Cugurullo, \& F. Caprotti (Eds.), Inside Smart Cities: Place, Politics and Urban Innovation (pp. 1-12). London: Routledge.

Karvonen, A., \& van Heur, B. (2014). Urban laboratories: experiments in reworking cities. International Journal of Urban and Regional Research, 38(2), 379-392. https://doi. org/10.1111/1468-2427.12075

Kitchin, R. (2014). The real-time city? Big Data and smart urbanism. GeoJournal, 79(1), 1-14. https://doi.org/10. 1007/s10708-013-9516-8

Langley, P., \& Leyshon, A. (2017). Platform capitalism: the intermediation and capitalisation of digital economic circulation. Finance and Society, 3(1), 11-31. https://doi.org/ 10.2218/finsoc.v3i1.1936

Lejano, R. P. (2019). Climate change and the relational city. Cities, 85, 25-29. https://doi.org/10.1016/j.cities.2018.12. 001

Leszczynski, A. (2016). Speculative futures: cities, data, and governance beyond smart urbanism. Environment and Planning A: Economy and Space, 48(9), 1691-1708. https://doi.org/10.1177/0308518X16651445

Levenda, A. M. (2019). Mobilizing smart grid experiments: policy mobilities and urban energy governance. Environment and Planning C: Politics and Space, 37(4), 634-651. https://doi.org/10.1177/2399654418797127
Levenda, A. M. (2018). Urban living labs for the smart grid: Experimentation, governmentality and urban energy transitions. In S. Marvin, H. Bulkeley, L. Mai, K. McCormick, \& Y. Yoytenko Palgan (Eds.), Urban Living Labs: Experimenting with City Futures (pp. 52-73). London: Routledge.

Lin, Z. (2018). Ecological urbanism in East Asia: a comparative assessment of two eco-cities in Japan and China. Landscape and Urban Planning, 179(November), 90-102. https://doi.org/10.1016/j.landurbplan.2018.07.008

Lin, Y. (2019). E-urbanism: e-commerce, migration, and the transformation of Taobao villages in urban China. Cities, 91(August), 202-212. https://doi.org/10.1016/j.cities. 2018.11.020

LingingAPI website (2020) Alibaba Cloud City Brain 3.0 released. Zhang Jianfeng: new digital infrastructure is the foundation of future urban evolution. https://www. linkingapi.com/alycsdnfbzjfszxjjswlcsjhgj/

Miao, J. T., Phelps, N. A., Lu, T., \& Wang, K. C. (2019). The trials of China's technoburbia: the case of the Future Scitech City Corridor in Hangzhou. Urban Geography. https:// doi.org/10.1080/02723638.2019.1613138

Min, W., Yu, L., Yu, L., \& He, S. (2018). People logistics in smart cities. Communications of the ACM, 61, 54-59. https://doi.org/10.1145/3239546

Mouton, M. (2020). Worlding infrastructure in the Global South: Philippine experiments and the art of being 'smart.' Urban Studies. https://doi.org/10.1177/ 0042098019891011

Murakami Wood, D., \& Mackinnon, D. (2019). Partial platforms and oligoptic surveillance in the smart city. Surveillance \& Society, 17, (1/2), 176-182. https://doi.org/ https://doi.org/10.1177/0038026120954785

Nyqvist, A. (2017). Scheduled schmoozing: notes on interludal practices at responsible investors' conferences. In $\mathrm{H}$. H. Leivestad \& A. Nyqvist (Eds.), Ethnographies of Conferences and Trade Fairs (pp. 23-42). Cham: Springer.

Nyqvist, A., Leivestad, H. H., \& Tunestad, H. (2017). Individuals and industries: large-scale professional gatherings as ethnographic fields. In H. H. Leivestad \& A. Nyqvist (Eds.), Ethnographies of Conferences and Trade Fairs (pp. 1-21). Cham: Springer.

Sampson, H., \& Turgo, N. N. (2018). Finding the way into a global industry: the usefulness of elite events to social science researchers. Journal of Organizational Ethnography, 7(1), 2-15. https://doi.org/10.1108/JOE-04-20170022

Paasi, A. (2004) Place and region: looking through the prism of scale. Progress in Human Geography, 28 (4), 536-546. https://doi.org/10.1191/0309132504ph502pr

Parks, D., \& Rohracher, H. (2019). From sustainable to smart: re-branding or re-assembling urban energy infrastructure? Geoforum, 100(2019), 51-59. https://doi.org/10.1016/j. geoforum.2019.02.012

Pow, C. (2018). Building a harmonious society through greening: ecological civilization and aesthetic governmentality in China. Annals of the American Association of Geographers, 108(3), 864-883. https://doi.org/10.1080/24694452. 2017.1373626

Rossi, U. (2020). Fake friends: the illusionist revision of Western urbanology at the time of platform capitalism. Urban 
Studies, 57(5), 1105-1117. https://doi.org/10.1177/ 0042098018821581

Rossi, U. (2019). The common-seekers: capturing and reclaiming value in the platform metropolis. Environment and Planning C: Politics and Space, 37(8), 1418-1433. https://doi.org/10.1177/2399654419830975

Robinson, J. (2015). 'Arriving at' urban policies: the topological spaces of urban policy mobility. International Journal of Urban and Regional Research, 39(4), 831-834. https://doi. org/10.1111/1468-2427.12255

Rose, G., Raghuram, P., Watson, S., \& Wigley, E. (2020). Platform urbanism, smartphone applications and valuing data in a smart city. Transactions of the Institute of British Geographers. https://doi.org/10.1111/tran.12400

SadowskI, J., \& Bendor, R. (2019) Selling smartness: corporate narratives and the smart city as a sociotechnical imaginary. Science, Technology, \& Human Values, 44 (3), 540-563. https://doi.org/10.1177/0162243918806061

Schuldt, N., \& Bathelt, H. (2011) International trade fairs and global buzz. Part II: Practices of global buzz. European Planning Studies, 19(1), 1-22. https://doi.org/10.1080/ 09654313.2011 .530390

Shelton, T., \& Lodato, T. (2019). Actually existing smart citizens: expertise and (non)participation in the making of the smart city. City, 23(1), 35-52. https://doi.org/10.1080/ 13604813.2019.1575115

Shelton, T., Zook, M., \& Wiig, A. (2015). The 'actually existing smart city.' Cambridge Journal of Regions, Economy and Society, 8(1), 13-25. https://doi.org/10.1093/cjres/rsu026

Simmons, G., Giraldo, J. E. D., Truong, Y., \& Palmer, M. (2018). Uncovering the link between governance as an innovation process and socio-economic regime transition in cities. Research Policy, 47(1), 241-251. https://doi.org/ 10.1016/j.respol.2017.11.002

Srnicek, N. (2016) Platform Capitalism. Cambridge, Polity.

Swyngedouw, E. \& Heynen, N. (2003) Urban political ecology, justice and the politics of scale. Antipode: A Radical Journal of Geography, 35(5), 898-918. https://doi.org/10. 1111/j.1467-8330.2003.00364.x

Torrens, J., Johnstone, P., \& Schot, J. (2018). Unpacking the formation of favourable environments for urban experimentation: the case of the Bristol Energy Scene. Sustainability, 10(3), 1-28. https://doi.org/10.3390/su10030879

van der Graaf, S. (2018). In Waze we trust: algorithmic governance of the public sphere. Media and Communication, 6(4), 153-162. https://doi.org/10.17645/mac.v6i4.1710

van der Graaf, S., \& Ballon, P. (2018). Navigating platform urbanism. Technological Forecasting and Social Change, 142, 364-372. https://doi.org/10.1016/j.techfore.2018.07. 027

van der Heijden, J. (2016). Experimental governance for lowcarbon buildings and cities: value and limits of local action networks. Cities, 53, 1-7. https://doi.org/10.1016/j.cities. 2015.12.008
Voorberg, W. H., Bekkers, V. J. J. M., \& Tummers, L. G. (2015). A systematic review of co-creation and co-production: embarking on the social innovation journey. Public Management Review, 17(9), 1333-1357. https://doi. org/10.1080/14719037.2014.930505

Wang, J. (2019). Stereotyping in representing the 'Chinese dream' in news reports by CNN and BBC. Semiotica, 226, 29-48. https://doi.org/10.1515/sem-2016-0150

Wiig, A. (2015). IBM's smart city as techno-utopian policy mobility. City, 19(2-3), 258-273. https://doi.org/10.1080/ 13604813.2015.1016275

Wu, F. (2002) China's changing urban governance in the transition towards a more market-oriented economy. Urban Studies, 39, (7),1071-1093. https://doi.org/10.1080/ 00420980220135491

Wu, F. (2012). China's eco-cities. Geoforum, 43(2), 169-171. https://doi.org/10.1016/j.geoforum.2011.08.001

Wu, X., \& Gereffi, G. (2018). Amazon and Alibaba: Internet governance, business models, and internationalization strategies. In R. van Tulder, A. Verbeke, \& L. Piscitello (Eds.), International Business in the Information and Digital Age (pp. 327-356). Emerald Publishing Limited: Bingley.

Wu, Y., Zhang, W., Shen, J., Mo, Z., \& Peng, Y. (2018). Smart city with Chinese characteristics against the background of big data: idea, action and risk. Journal of Cleaner Production, 173, 60-66. https://doi.org/10.1016/j.jclepro. 2017.01.047

Ye, X., \& He, C. (2016). The new data landscape for regional and urban analysis. GeoJournal, 81, 811-815. https://doi. org/10.1007/s10708-016-9737-8

Yeung, Y.-M., Lee, J., \& Kee, G. (2009). China's special economic zones at 30. Eurasian Geography and Economics, 50(2), 222-240. https://doi.org/10.2747/1539-7216.50.2. 222

Zhang, J., Hua, X.-S., Huang, J., Shen, X., Chen, J., Zhou, Q., et al. (2019). City brain: practice of large-scale artificial intelligence in the real world. IET Smart Cities, 1(1), 1-10. https://doi.org/10.1049/iet-smc.2019.0034

Zhejiang Online (2018) The city's brain has changed the 'Hangzhou answer' that the whole country has come to listen to the city's governance. Zhejiang Online 21 November 2018. Available at: https://js.zjol.com.cn/ ycxw_zxtf/201811/t20181120_8795928.shtml (2019).

Zhen, F., Wang, B., Wei, Z. (2015) The rise of the internet city in China: Production and consumption of internet information. Urban Studies, 52 (13), 2313-2329. https://doi.org/ $10.1177 / 0042098014547369$

Publisher's Note Springer Nature remains neutral with regard to jurisdictional claims in published maps and institutional affiliations. 